\title{
Authority - the Enemy of Freedom?
}

\author{
DOI: $10.35757 /$ CIV.2009.11.09
}

Theodor Adorno once wrote that authority always has a "moment of the horrifying". He accused authority of having a totalitarian tendencies and claimed that, all possible benefits notwithstanding, authority is always evil. Adorno's maxim did not become popular because it was very original or paradoxical, but because it expressed sentiments concerning authority which were quite widespread at the time. It is difficult to establish unequivocally why authority evokes such negative connotations. Is it because often, at least in the political sphere, it is linked to a coercion that constrains a broadly defined and absolutized notion of freedom? Or because it seems that it results in subordination and dependence, which evoke either a humiliating and scandalous slavery or an equalitydenying hierarchy? Or perhaps because arbitrariness is always an immanent element of authority which can, admittedly, be limited or concealed, but which can never be completely negated? Authority's historical manifestations, especially in the $20^{\text {th }}$ century, do not contribute to the amelioration of these negative sentiments. The use of authority often leads to its abuse, and though the frequency argument is not philosophically conclusive, nor can it be altogether ignored.

This negative vision of authority might be easier to explain if we could at least agree upon the historical development of the

Tomasz Merta - historian of political thought, Ph.D. at the Faculty of Applied Social Sciences at the University of Warsaw, under-secretary of State in Polish Ministry of Culture and National Heritage. 
idea. This is of no use, however, because the history of authority is recounted through many different, incompatible and sometimes simply contradictory versions. There are accounts proclaiming the triumphal march of freedom through history, which emancipates individuals from authority to an ever-greater degree. At the same time, there is the view that authority's might has not been diminishing with the flow of time, but instead steadily growing, and reached its culmination in $20^{\text {th }}$ century totalitarianism. There are also explanations which claim that authority neither disappears nor grows, but only undergoes a metamorphosis: the bloody despotism of the tyrants gives way to the mild despotism of the welfare state. Finally, we have the explanations offered by authority-hunters (the word "hunter" is entirely appropriate here, because they speak to us in a sort of mysterious native-Indian dialect) who follow Foucault in hunting down political authority in all spheres of human activity, in every human act, belief and word. Their enthusiasm prevents them from noticing that their all-encompassing definition of authority only leads to a vicious circle, in which the theory of a pervading authority itself becomes part of the hidden authority which has to be unmasked.

However, our world is not built from authority molecules evenly dispersed in all that exists. Authority is not persuasion and coercion is not rhetoric. We do not gain anything by describing the various means of influencing people with one word. Therefore, let us leave the authority-hunters aside in our discourse, with this remark: that they too are mistrustful of authority and sometimes even openly antagonistic.

This consonance of negative sentiments does not, however, mean that authority is not a controversial matter. It is; but its controversiality is of a peculiar kind, in which it is not a question of whether authority is good or bad, but whether it is a lesser or a greater evil. Or more accurately, whether it is a necessary or an unnecessary evil. The diverse opinions in this matter have their 
origin in different anthropological visions of man. One group, which tends to be much more optimistic in its assessment of human nature, professes all authority to be superfluous. The anarchic utopia is presented as the alternative to authority, the utopia of a spontaneous order founded upon agreements established in each particular moment by the members of a given society. The second position, which is more pessimistic of human nature, sees authority as a necessary element, which superimposes order on the chaos of reality, and in so doing creates suitable living conditions by protecting humans from each other. The first conception sees authority as an enemy or, more precisely, as an unjustified destroyer of freedom. The second sees it as a strict father who protects his child for his own good, but in order to do this he justifiably restricts the child's freedom. The dispute between these two positions is usually resolved through a process of painful reflection: the first position is rejected as being unlikely and unrealistic, while the second is accepted as uncomfortable but necessary. So the entire matter ends with a cliché: that we must restrict some of our freedom in order to save the greater part. In summary: as much freedom as possible and only as much authority as necessary. This debate having been concluded, the only thing left to do is negotiate the technical details in order to give the principle a concrete form. In this way, history becomes no more than a record of such technical negotiations, during which the scope of authority's intervention is delimited and the complementary dimension of human freedom is specified. If one can say that we are dealing here with a process of emancipation, it is certainly not a process of emancipation from authority as such, but from its forms which are deemed unjust or superfluous.

To say that something is a cliche actually serves to support rather than to refute it. After all, a cliché often owes its triviality to the fact that a given judgment is believed to be not only indisputable, but actually obvious. Even so, it is good to reflect upon theories which propose different solutions to the problem of 
authority's legitimization, because these theories take a different approach in defining the functions of authority, and consequently place it in a completely different relationship to freedom. It is not surprising that these other solutions remain to a greater or lesser degree within the boundaries of classical political philosophy, in which authority was always a part of the natural order. Of course, one could remark that for Hobbes and Locke authority is also natural to a certain degree. This, however, is the type of 'natural' which is characteristic of a necessity incumbent upon individuals. They must choose authority and subordinate themselves to it if they are to live in peace. This 'natural' is therefore actually an artifice. It is the work of human hands, or rather, of human minds. It is the result of an established contract. Classical philosophy, on the other hand, taught that authority of some kind exists always and everywhere, and that it is natural in the same sense as any phenomenon whose existence does not require the involvement of human free will.

Does it make any sense to invoke this old thought paradigm? The answer to this question depends on the character of political philosophy. If political philosophy is a linear science which attempts to falsify and reject old theories and to propose new ones (which are more precise and more difficult to refute, or even irrefutable), than searching for such inspiration is absurd. In this case, the status of ancient or medieval political philosophers would be no different than that of the precursors of modern-day medicine or chemistry. We can state with a high degree of probability, however, that this is not the case. Political philosophy is not a linear science, but rather a capricious being which sometimes suddenly interrupts a debate for reasons which are not altogether rational and focuses its attention on new matters without having resolved previous ones. If this is indeed so, then nothing in this field can be considered definitively refuted. Old languages can be revived and former theories defended anew. Dead opinions can be resurrected if only we know how to express 
them in a contemporary language. Let us now consider two such projects, one of a smaller and one of a larger scale.

In Political Justice Ottfried Höffe considers the problem of a normative justification of authority by contrasting it with the beliefs professed by proponents of anarchy ${ }^{1}$. He sees the history of thought on authority in the context of two ideals: the ideal of just authority and the ideal of freedom from authority. The former has been a part of political reflection from the outset. The latter has appeared only relatively recently. Höffe links its appearance to the formation of a negative conception of authority as an institution which connotes lawlessness, oppression and exploitation, and, most of all, which builds relations of submission, master-slave type relations. Höffe also proposes an interesting hypothesis about why this has occurred. In ancient Rome, the right to command a subject or a citizen (imperium) was distinct from the right to private property (domini). This distinction has become gradually blurred, and this has led to a situation in which the relations of a prince to his subjects resemble those of private property. As a result, anyone who obeys orders and who has to subject himself to authority has been reduced to the status of a slave. There is therefore nothing strange about the aversion toward authority which emerged at this time. It should also be noted that the right to command, proper to the feudal system, still upheld the distinction between these two rights, the right to command and the right to private property. The relation between sovereign and vassal was a relation of mutual rights and obligations in which the dignity of both persons was respected.

Thus, emancipation in Höffe's opinion would be not so much an emancipation from authority as such, but from an authority which treats its subjects as if they were its private property. Therefore, it is less a matter of rejecting obedience than of an obedience which in such a relation has become a negation of subjectivity.

Otfried Höffe: Political Justice: Foundations for a Critical Philosophy of Law and the State, Polity Press, Cambridge 1995. 
Höffe considers two possibilities for a normative justification of authority: the model of cooperation and the model of conflict. The model of cooperation was proposed by Plato and Aristotle. Plato invoked the image of a perfect state consisting of a cooperative working community aspiring to satisfy its needs and combat the destructive force of the appetites through moral education and culture. Aristotle, in turn, described the polis as a natural community, a community with its own agathon, a community within which man's end is not only self-preservation, but also the attainment of a happy life. Thus, Höffe believes that Aristotle's vision is more complete than Plato's: "the legal community and the community of the state are not just to correct the state of need of the manifold dependence of the individual. It is also the place in which man's humanity can be fully realized."

Nevertheless, Höffe believes that the model of cooperation cannot constitute a justification for the existence of authority. It only proves the necessity for human cooperation, for some form of shared or social coexistence. A normative justification for authority can only be found based upon the model of conflict. Even Aristotle, when he provides the true justification of authority, makes reference to this model. The model of conflict appears in its purest form at the beginning of modern times. For Hobbes, individuals in the state of nature, guided by the desire for self-preservation and the fear of death, which endangers them all to an equal degree, finally relinquish some of their freedom and submit themselves to the coercion of an authority established through a contract in order to obtain peace.

Höffe is skeptical about Hobbes's description of the state of nature because many of its elements are in fact highly doubtful, and the resulting vision of man is unjustifiably reductionist. He instead proposes a new description of the "state of nature," in other words, of the pure human condition. In this redefined state of nature the only principle in force is full freedom of action; the only law is pure free choice formed by the subjective free will 
of each individual independently. In this situation the source of conflict in the state of nature is born less of human desires - such as the desire to rule - than of the pure desire to realize one's own subjectivity, that is, to make use of one's freedom. "The freedom of action of some individuals must always be limited by the freedom of action of others, which means that both cannot coexist at the same time." ${ }^{2}$ Thus this original, natural coexistence creates a conflict whose practical consequence is the appearance of social coercion. Coercion does not have to be actual aggression in this case, yet it is always present as a naturally occurring constraint of one individual's freedom by others.

So it turns out that coercion and the constraint of freedom are present in society before authority appears. Thus authority does not so much limit freedom, but only puts this limitation in order and confers stable and permanent rules upon it. The field of liberty is constrained, but not by authority. One could even wonder if we don't fall into a sort of delusion if we speak of a limitation of freedom, since this limitation is an essential part of our relations with others and appears naturally, and not through human will. Obviously, one could argue that our lack of wings and capacity for flight limits our freedom. However, this has a different meaning (if it has any meaning at all) from the limitation of freedom of someone who is imprisoned or deprived of the freedom to move about freely. Authority in Höffe's conception only administers already existing limitations. The author of Political Justice writes: "The community which establishes a renouncement of parts of freedom for the benefit of all and which enforces this renouncement in case of necessity is not an unrightful violence but rather a condition for creating a valid existence."

Höffe thus sees the ideal of liberty from authority as completely unrealistic and underlines even more the necessity for striving for the ideal of a just authority. Just authority aims to create an

Ibidem, p. 286-287

3 Ibidem, p. 374. 
obligatory structure to guide the citizens' actions along certain paths. It proposes certain modes of behavior and educates. However, Höffe does not follow Aristotle here in the latter's attempt to formulate an objective definition of happiness. The common good, which is authority's main checkpoint, is reduced to the creation of a general and just legal framework without indicating which manner of living is most advisable. It is a matter of defining the extent of permitted social action, and of indicating actions which must be punished for the good of the whole. Besides, Höffe proves that, for Aristotle, the objective notion of happiness was not the only possible legitimization of the polis anyway. "Aristotle develops the objective concept of happiness but does not need it in his justification of the polis: because cooperation and diversity are beneficial also to those who seek their happiness in strategies of life which Aristotle believes to be objectively erroneous, such as the pursuit of a life of pleasure or of a merchant instead of seeking a theoretical or politically-moral existence."

An authority which creates the general rules of social life and delimits and sets the scope of an individual's partial renouncement of his freedom is no longer the Leviathan. It is Justitia. The sword has been counterbalanced by the scales. Yet though this authority cannot be accused of bearing an innate hostility towards freedom, it cannot expect excessive benevolence. Höffe writes that, "Institutions are criticized because they satisfy needs and interests. They encounter opposition because they separate this fulfillment from the momentary motives and intentions of the individual and subordinate them to the structure in force." ${ }^{5}$ Höffe's proposal, while convincing on the fundamental question of the existence of a limitation of freedom previous to authority, is a bit idyllic in its views. Justitia, just authority, carries the promise of freeing us from the arbitrariness and subjectivism of those who rule. However this promise can never be fully carried out. The forceful

Ibidem, p. 261

5 Ibidem, p. 310. 
imposition of political decisions will not be eliminated, even if we entrust political matters to experts or judges. The political can be transferred, but never eliminated. It has already moved from the throne room to the parliament, and now it is moving from the parliament to the constitutional court. Under no circumstance, however, does this signify an elimination of arbitrariness or a removal of the political. The emotions which in many countries accompany judges' constitutional court nominations and the expansion of their prerogatives give testimony to this fact.

The second proposal for a favorable vision of authority precedes the first one and is more far-reaching. Its author is Yves Simon, a personalist philosopher and friend of Maritain, who was gifted with an original and inquiring mind, but whose writings unfortunately exhibited a heavy-handed style. One less reads his works than plows his way through them.

Simon's main aim is to argue against the view that authority has never resulted from man's and society's positive traits. Authority has many different functions, yet it is often reduced to only one: the substitutive function by which, because of the weakness of human nature, authority replaces people in their mutual relations. An authority whose justification resides in the imperfection of human nature is a parental authority which limits its subjects and acts in their place in many undertakings and decisions. Parental authority is akin to a father's authority, but is different in that a father's authority is intended to cease one day. When the child becomes independent and frees himself from the limitations of immaturity, the father's authority loses its legitimacy and actually becomes abuse. Parental authority lasts just as long as the imperfection of human nature, which is its cause. People feel imprisoned in a state of childhood and view authority as hostile and humiliating because it requires obedience and limits freedom. Paternal authority is natural only conditionally: just like a father's authority, it would lose its justification if people freed themselves from the defects of their nature. 
Simon demonstrates that it is an error to reduce authority to its substitutive function. In his opinion there are other functions which demonstrate the unqualified natural character of authority as a factor making social co-existence possible. Authority is foremost a cause of common action. Elaborating on Thomist thought, Simon sees common action as one of the fundamental paths for the true expression of human freedom. Common action emerges as the result of a shared judgment, and this can only be achieved through consensus or the intervention of authority. Of course, it is not hard to imagine a situation in which a consensus is formed due to particular circumstances: if a besieged nation defends itself, the question of the common good is less than divisive for the members of the besieged community. However, even agreement upon the common good can be insufficient for common action. This is because there can be disagreement about the means which should be applied to obtain the common good. A situation in which the community chooses between truly appropriate means and only apparently appropriate means is of little interest here. In this case authority becomes necessary, because the members of the community are not able to discern what their true good is or what the proper means for achieving this good are. However, here we would still be dealing with authority's substitutive function, which results from the imperfection of human nature. Much more interesting is the situation where several different means can all lead to the attainment of the good. Family vacations can be organized both by the sea and in the mountains. If no clear circumstances mandate a preference for one of these options, a choice must be made between equally appropriate means. The choice itself is necessary because this is an obvious condition for common action. In this situation a system for making decisions and for enforcing them is necessary, and this is why authority can be defined as a cause of common action in cases where consensus is unobtainable or only accidental. Therefore, Simon 
defines authority as a "force responsible for the unification of common action through rules which are binding for all."

Simon goes even further. He states that authority's function exists not only in relation to the means that permit the carrying out of a common good through common action, but also in relation to the common good itself. In other words, authority's function also deals with the question of determining common action's objective. If the common good is not the sum of individual goods but something different, then it we take for granted that this good will be spontaneously fulfilled in every circumstance. Simon, following Thomas Aquinas, distinguishes between the formal and the substantial or material intention of the common good. Every member of society has an obligation to strive for the common good formally understood. At the same time, there is no obligation to strive with equal vigor for the common good materially understood. The latter is primarily the competence of authority and of public persons. In one of Simon's examples, the wife of a man condemned to death for murder does not rest in her efforts to save him, even though the criminal's death is undoubtedly materially a common good for the community. However, in so doing, she fulfils the common good's formal intention, because she acts exactly as society would expect a wife to act. For Simon, "the common good formally understood is the concern of every genuine virtue, but it is the proper concern of the public person to procure the common good materially understood, which the private person may virtuously oppose."7

In the example just mentioned, we had the case of a person who sought the good in the formal intention, and fell into conflict with the demands of the material common good. Just as often, however, we are faced with a different situation, where someone does not act in contradiction to the common good materially

\footnotetext{
${ }^{6}$ Y.R. Simon: A General Theory of Authority, University of Notre Dame Press, Notre Dame, IN 1980, p. 33.

7 Y.R. Simon: Philosophy of Democratic Government, University of Notre Dame Press, Notre Dame, IN 1980 (http://maritain.nd.edu/jmc/etext/pdg-1d.htm).
} 
understood, but carries it out only partially. A good school teacher of Latin usually does not try to convince his students that his subject is of minor importance and actually superfluous. On the contrary, he tries to infect them with his passion and to convince them that there is nothing more important than learning the language which opens the doors to classical studies. It is not his responsibility to maintain an equilibrium, or to watch over the harmony of the entire educational process and to ensure that it is in accordance with what society expects. These are rather the obligations of the school's authority, the school's principal, or the common authority of the school council. Therefore, authority is responsible for ensuring the harmony of the various functions and elements of the common good, and for an equilibrium, so that all of the school's students will not in fact become die-hard Latin enthusiasts. Incidentally, that same Latin teacher could have just such an obligation acting in a different capacity, for example as a member of the common authority which is the school council. In this case, his obligation would be to distinguish between his personal preferences and to judge all matters from the perspective of the common good materially understood. Simon's conclusion is that, "Authority's most essential function is the issuance and carrying out of rules expressing the requirements of the common good considered materially." 8 Thus, "Considered in its essential functions, authority is neither a necessary evil nor a lesser good nor a lesser evil nor the consequence of any evil or deficiency - it is, like nature and society, unqualifiedly good."

The difficulties which result from Simon's approach are rather obvious. First and foremost, freedom, even though it is often invoked, actually dissolves in the community. If one can speak about some form of freedom here, it is more the form of positive freedom than the freedom of choice or the freedom to rule oneself by one's own means. Simon emphasizes that the

Y.R. Simon: A General Theory..., p. 57.

9 Y.R. Simon: Philosophy... . 
principle of authority must be accompanied by the principle of autonomy: "The perfection of autonomy rescues the particularity of the subject and of any forms of authority which are necessary to maintain this autonomy. Known contrasts disappear in this case. Authority and autonomy are no longer in conflict and are no longer opposed to each other." 10 This is true, but this "no longer opposed to each other" is probably based on a significant reduction of the force and meaning of freedom, whose notion is transformed into a hampered autonomy. The champion of freedom has turned her into his captive. Perhaps at her willing and in accordance with the natural state of things, but this does not change the fact that her freedom has been restricted.

We should also ask ourselves whether Simon's concept of the common good is acceptable. In his philosophy, it is an independent good and cannot be reduced simply to ensuring that the members of society have the possibility of freely carrying out freely determined and individual ends. We could probably venture to say that Simon's common good is possessive and engages everyone much more than the liberal common interest in any one of its numerous forms. It does not, however, seem to be a long way from the common good of the republican tradition, which is above all the effort to ensure the permanence of the community, because the community is immortality's temporal surrogate.

Another matter is the problem of truth, and especially of practical truth. Is authority capable of recognizing such truth? The entire sense of this construct basically depends on the answer to this question. It would be difficult legitimize authority's unconditional pursuit of the material common good if the possibility of discerning what constitutes that very good were uncertain. Simon explicitly resolves the matter of theoretical truth. In this regard authority only has a substitutive function, and the most it can do is to proclaim and support it. However, the author of Philosophy of Democratic Government insists that it is possible to gain

\footnotetext{
${ }^{10}$ Y.R. Simon: A General Theory..., p. 54.
} 
certain knowledge in practical matters. Only that the certainty related to practical truth is, so to speak, somewhat less certain. "The conformity of a practical proposition with the real cannot be perfectly established; but such conformity is absolute truth, theoretical truth; it is not the truth that belongs to the practical proposition qua practical. Practical truth is a relation of conformity between a judgment or a proposition and the requirements of an honest will. When a decision is what honesty demands that it should be, this decision is true in a practical sense, and its practical truth is certain and unqualified. The uncertainty of our calculations entails painful consequences, but it does not affect the possession of practical truth, which retains its firmness amid ruins." 11 Well, the authority's actions require a recognition of the practical truthfulness of their decisions amid ruins much too often for us to accept this conclusion as fully convincing. Simon would surely reply that cases of abuse of authority or of authority's mistaken decisions are irrelevant here because philosophy deals with what is necessary, and not what is accidental. However, it is difficult to convince those whose life is to a large extent determined by accidentality that authority is an unconditional good.

Nevertheless, if we criticize Simon, or at least some of his philosophy's premises, we should also say something about his opponents. I have the impression that their premises are generally believed to be certain even though they are not in fact so. Hobbes's description of human nature requires the reader to accept half-truths and simplifications just as much as Simon's definition of the common good. The matter is even worse in the case of contemporary philosophers.

Is it possible to change the way relations between authority and freedom are portrayed? Will authority (or at least the common good) ever again be treated as something natural in the same way that it was in antiquity or during the Middle Ages? Surprisingly,

11 Y.R. Simon: Philosophy... . 
in Simon we discover a touch of relativization of this problem which will surely appeal to those who see man as a plaything of the laws of history: "Treating the common good as something merely utile is proper to times of crisis, but as soon as the need for a new organic period is strongly felt, the presentation of the common good as a simple means without any dignity of its own becomes unbearably paradoxical." ${ }^{2}$ Seen from standpoint, the problems of authority, freedom and common good are of no great significance. Instead, it is better to ask ourselves which moment we presently find ourselves in. At the beginning of a period of crisis or perhaps at its end?

Translated by Pawet Janowski

First edition: Władza-wróg wolności, "Civitas. Studia z Filozofii Polityki” 2001, vol. 5, pp. 104-118.

${ }^{12}$ Y.R. Simon: A General Theory..., p. 47. 